\title{
A EXPULSÃO DOS JUDEUS DA ESPANHA NAS CRÔNICAS CRISTÃS DA ÉPOCA (1492)
}

Maria Guadalupe Pedrero-Sánchez’

SÍNTESE - No final do século XV, sob o reinado de Fernando e Isabel, houve a grande expulsão dos judeus espanhóis. Os cronistas da época tendem a silenciar sobre o fato, quando não a elogiar a atitude dos monarcas. No máximo, alguns apresentam o fato como um mal menor. Também os intelectuais da época, e até a universidade de Paris, tiveram palavras de louvor à atitude dos reis.
ABSTRACT - At the end of the fifteenth century, when Ferdinand and Isabella reigned, Spanish jews were expelled from Spain. The chroniclers of this time tend to hide under silence the event or show a tendancy to praise the attitude of the monarchs. At most, some of them exhibit the occurrence as an evil of minor importance. The intellectuals of this time and also the university of Paris have praised the way of acting of the kings.

"Deus nos guarde de maldizer aos nossos reis, pois eles são o nosso escudo, o nosso broquel e o nosso refúgio; eles nos protegem de todas as desgraças. Se estivéssemos em poder da multidão e esta não temesse a Coroa, não teriamos salvação." (Rabi Mose ha-Cohen de Tordesillas. Ezer-ha-Emuná. 1375)

A experiência vivida pelos judeus de Sefarad em 1391, ano em que ocorrem as primeiras matanças generalizadas na Espanha, coincide com a morte do rei João II de Castela. É assim que para os judeus, sem rei e expostos à multidão, confirmam-se amplamente as palavras e os temores expressos por Mose haCohen, dezesseis anos antes.

Nesse contexto, a restauração da autoridade monárquica estabelecida por Isabel e Fernando a partir de 1474 representava para os judeus a garantia de que já não estariam expostos aos saques e violências de 1391. Porém, implicava também o surgimento de uma nova proposta política: a formação de uma nação moderna que exigia a coesão do corpo social, e esta, na época que consideramos, só poderia ser de ordem religiosa.

Departamento de História. UNESP. Campus de Assis - SP.

\begin{tabular}{|l|l|l|l|l|l|} 
VERITAS & Porto Alegre & v. 42 & $\mathrm{n}^{0} 3$ & Setembro 1997 & p. 711-717 \\
\hline
\end{tabular}


Por outro lado, cinco anos antes do Edito de expulsão da Espanha em 1492, os judeus espanhóis dirigindo-se à comunidade de Roma congratulavam-se por estarem submetidos a reis tão justos e tão bem dispostos para com eles.

O que desencadeou uma mudança tão grande como para chegar à expulsão? Essa data marca um ponto de inflexão em Sefarad e introduz numa série de paradoxos de difícil compreensão, ainda não resolvidos totalmente, não só no que se refere à história dos judeus sefardins, mas à história posterior da Espanha.

A expulsão dos judeus é considerada como a etapa final de um processo, não cabendo atribuir este acontecimento ao antijudaismo particular de Isabel e Fernando, como bem pode ser verificado na documentação da época.' Três aspectos aparecem como imprescindíveis para entender o contexto:

$\left.1^{\circ}\right)$ A colaboração e aliança dos judeus com aqueles que defendiam o restabelecimento da autoridade real, da centralização e da ordem que foi uma constante ao longo da Idade Média espanhola. Basta lembrar alguns exemplos: Samuel ha-Leví junto a Pedro I, os conversos de Toledo apoiando don Alvaro de Luna e, ao lado dos Reis Católicos, Abrahan Seneor e Isaac Abravanel.

$2^{\circ}$ ) A existência de uma crescente hostilidade popular, manipulada e demagogicamente explorada em conflitos sócio-políticos concretos, como na luta fratricida entre Pedro I e Henrique II. Hostilidade que se faz irreversível e marca uma degradação progressiva nas relações judeu-cristãs.

$3^{\circ}$ ) O projeto político de Isabel e Fernando exigia a coesão do corpo social que supunha a formação de um estado moderno unido e homogêneo, não só geopoliticamente, mas também, ideológica e culturalmente, e este, sob a orientação religiosa.

Até o decreto de expulsão, existem dois grupos de pressão na Corte: um minoritário que defende a permanência dos judeus e a moderação com relação aos judeus e conversos, e outro que luta pela extinção do judaísmo. Este último passará a ser liderado pela Inquisição, cuja implantação em 1480 marca a primeira fase de extinção do judaísmo, sendo a segunda a série de expulsões parciais realizadas na Andaluzia em 1483 por essa mesma instituição. ${ }^{2}$

Limitando-nos ao reinado de Isabel e Fernando, encontramos judeus e conversos trabalhando ativa e eficazmente pela candidatura de Isabel. O papel desenvolvido por Abraham Seneor e o converso Andrés Cabrera serve como exemplo.

Um cronista posterior, Clemencin, no seu Elogio de la Reina Católica Doña Isabel afirma: "Em palácio serviam na imediação da rainha e gozavam do seu favor e confiança os secretários Fernando Alvarez, Alfonso de Avila e Hernando del Pulgar, todos os três cristãos novos".

Ao abordarmos a historiografia dessa época e as Crônicas relativas a Isabel e Fernando, não se pode deixar de considerar o "mito" construído em torno destes monarcas, porque estará presente em todas elas. Apesar da expulsão dos judeus e

SUAREZ FERNANDEZ, L. Documentos acerca de la expulsión de los judios. Madrid, 1964.

M. Guadalupe PEDRERO. Os Judeus na Espanha. São Paulo: Giordano, 1994, p. 97 - 108 (A Expulsão e A Inquisição e os judeus)

3 Diego CLEMENCIN. "Elogio de Isabel la Católica e Iustraciones sobre varios asuntos del reinado de doña Isabel la Católica”. In Mémorias de la Academia de la História, VI, 1820. 
da Inquisição, o seu reinado, como um todo, teve sempre favorável acolhida, tanto na cronistica da época quanto na historiografia posterior.

Como todos os mitos, este teve, também, um fundamento real. A crise castelhana do século XIV e a decadência catalã e aragonesa durante o mesmo período concluiram-se com o matrimonio de Isabel e Fernando pela integração de Aragão e Castela. Trata-se, inicialmente, de uma união pessoal . Porém começa a surgir uma nova Espanha como entidade diferente, além da mera justaposição das duas Coroas. Exxitos espetaculares de ressonância européia, como a conquista de Granada, das Ihas Canárias, do triunfo na Itália, da chegada à América, consolidam o mito e abrem as portas da Europa, onde começam a participar como protagonistas e não mais como periferia da Cristandade.

Surge um nacionalismo historiográfico orientado para a construção de um estado centralizado. El Rei e a Rainha assumem juntos o projeto e trabalham pela sua realização por todos os meios: ação guerreira, diplomacia, religião e propaganda. Eles mesmos contribuíram para construir a sua imagem valendo-se de propagandistas - cronistas - a soldo.

O mito fundamenta-se em bases muito simples. Antes: nada, o caos, a anarquia; depois: ordem, segurança, unidade, prosperidade, justiça. Recolhendo palavras textuais do cronista Bernaldez: "Antes [...] mucha soberbia, mucha herejia, mucha blasfemia e avaricia e rapiña, muchas guerras e bandos e parcialidades, muchos ladrones e salteadores". Depois " tantos bienes e mistérios, tantas milagrosas cosas cuantas habeis visto e oido".

Este esquema está presente em todas as Crônicas da época, tanto as que saíram dos círculos oficiais, quanto as provenientes de cronistas locais. Aparece tanto naqueles que aderem fervorosamente ao programa da Inquisição, como Bernaldez, quanto naqueles que são partidários de uma ação mais moderada, como Alonso de Palencia, Diego de Valera ou Pulgar. Imagem ou mito recolhido também por escritores como Maquiavel ou Castiglione, para indicar alguns exemplos fora dos domínios dos Reis Católicos.

Se esta é a imagem que aparece predominantemente nas Crônicas com relação à monarquia renovada pelos Reis, podemos perguntar-nos também: Como aparece, nessas fontes, o tema da expulsão dos judeus? Qual é a repercussão desse acontecimento na historiografia da época?

Duas posturas predominam, o silêncio e a consideração da expulsão como mal menor. Quanto ao silêncio podem ser feitas algumas constatações. Alonso de Palencia ${ }^{6}$ interrompe o seu trabalho de historiador nesse ponto. Fernando del Pulgar termina a sua crônica em 1490, dois anos antes. Cabe perguntar-se: intelectuais e escritores não acharam outra alternativa? Silêncio, pois, apesar de conhecer, como veremos, posicionamentos claramente contrários na época.

" BERNALDEZ, A. "Memoria de los Reyes Católicos don Fernando y doña Isabel”. In Crônicas de los Reyes de Castilla, III. Cayetano Rossell (Ed.) Madrid: Atlas, 1953 (Biblioteca de Autores Españoles, 70) p. 574.

5 PALENCIA, Alonso de. Guerra de Granada. A. PAZ y MELIÁ (Ed.), Madrid, 1909. Apesar do título, esta obra abrange outros aspectos de reinado dos Reis Católicos. 
Quanto aos cronistas que registram o acontecimento, o apresentam como necessário e desculpam ou justificam tal ação. Dificilmente se encontram juízos ou condenações explicitas.

É apresentado como mal menor, visto com perspectiva pragmática a curto prazo. Os reis são conscientes e não estão plenamente satisfeitos com esta medida, por outro lado, muito refletida. Buscam justificativas para proteger a própria imagem. Descobrem-se numerosas vacilações na aplicação de medidas, como se demonstra pela implantação da Inquisição, a qual acontece dois anos após terem a bula de Sixto IV nas suas mãos, ou pela implementação de um novo projeto de evangelização conduzido por Hernando de Talavera e o Cardeal Mendoza. Desde a elaboração do edito de expulsão até a sua promulgação, deu-se uma demora de dois meses. Mas, uma vez que foi decretado, aparece como medida drástica e definitiva, bem ao estilo dos Reis em outros assuntos.

O edito, porém, não solucionou o verdadeiro problema dos conversos e deu lugar à polêmica sobre os cristãos novos que degeneraria na "limpeza de sangue". Colocou a Espanha numa trajetória completamente alheia à sua tradição. Instaurando-se a unidade da fé, instaura-se oficialmente uma mudança: da benevolência, à neutralidade, da tolerância, passou-se para a intransigência, o rigor, a perseguição.

Assiste-se a uma virada da política religiosa. A Espanha volta-se para a Cristandade européia, quando este conceito já está decadente, deixando de ser ponte entre Oriente e Ocidente. Foi vontade política? Sim e não, afirma Josep Perez na sua obra Isabel y Fernando. ${ }^{6}$

Em todo caso, a expulsão dos judeus introduziu uma série de paradoxos na História da Espanha da época e posterior. Como eliminar o problema dos conversos aumentando o número deles?. Por que se persegue somente um tipo de herege, o judaizante?. A Religião é um pretexto? Para quê? Como construir a unanimidade assentando as bases para a clandestinidade, a desconfiança, os desgastes psicológicos que naturalmente deviam surgir diante de uma pressão tão forte?

Por outro lado tem-se exagerado muito as conseqüências đa expulsão dos judeus para a Eśpanha. Os Reis não encheram as arcas com o seu exílio. Não representou uma catástrofe econômica (atingia de 4 a 5\%) e deve ser considerada como uma das muitas crises passageiras e localizadas. Os envolvidos no comércio internacional já eram conversos e não foram afetados.

Quanto à repercussão internacional, se a Cristandade assistiu aos infortúnios dos judeus, consolaram-se glorificando o triunfo da Igreja. Pico de la Mirandola refere-se ao Rei da Espanha em 1493 como "aquele rei cristão entre os cristãos, que estava além de todos os louvores". Guicciardini enumera a expulsão dos judeus entre as grandes obras dos Reis Católicos que tinham unificado a Espanha. Conhecida é a opinião de Maquiavel, sempre admirador absoluto de Fernando, para ele não podia haver um exemplo mais admirável e precioso de príncipe.

Uma das felicitaçôes mais calorosas pela decisão tomada com relação aos judeus e recebida pelos Reis, procede da Universidade de Paris, pela decisão tomada com relação aos mesmos. E, embora acolhidos à Corte Pontifícia, o título de Reis

- PEREZ, Joseph. Isabel y Fernando. Los Reyes Católicos. Madrid: Nerea, 1988, p.307. 
Católicos outorgado pelo Papa foi concedido em função da sua atuação com relação a mouros e judeus.

Tomaremos como referência dois exemplos concretos: um cronista, Fernando del Pulgar, e uma Crônica, Memoria de los Reyes Católicos don Fernando y doña Isabel de Andrés Bernaldez, para acompanhar os dois posicionamentos.

Fernando del Pulgar é de origem conversa, secretário da Rainha, conselheiro encarregado de missões diplomáticas na França e na Itália, cronista oficial, exercendo, na prática, as funções de agente qualificado do serviço de propaganda. Reside na Corte e acompanha os reis na sua viagem a Sevilha (1477-1478) onde os monarcas queriam examinar de perto e investigar pessoalmente as denúncias alarmantes que lhes enviara Frei Alonso de Hojeda sobre os conversos.

Pulgar é testemunha direta dos acontecimentos e forma parte do círculo de pessoas que, na Corte, aconselham a moderaçâo e temem as conseqüências de ações extremas e radicais. Integra o grupo formado pelo cardeal Mendoza e pelo confessor da rainha, Hernando de Talavera, também converso.

Em repetidas ocasiões fala de como “ Ë] Rey e la Reyna [...] ovieron grande pesar" e "estavan muy sentidos de la herejia", e alude às tentativas realizadas para impedir ações drásticas encaminhadas a corrigir os excessos; porém, diz ainda "äprovecho poco". Continuando a sua narrativa, escreve sobre a expulsão dos judeus da Andaluzia (1483):

"[...] E porque se achou que a comunicação que aquela gente tinha com os judeus que moravam nas cidades de Córdova e Sevilha, era alguma causa daquele erro, ordenaram el Rey e la Rayna, por constituição perpétua, que nenhum judeu, sob pena de morte, morasse naquela terra: os quais foram constrangidos a deixar as suas casas, e ir morar em outra parte"

O cronista narra a atuação dos primeiros inquisidores em Sevilha e o processo seguido pelos mesmos. Não poupa críticas tanto à Inquisição, quanto à forma de proceder dos inquisidores que qualifica como rigorosa, cruel e parcial, motivada pelo ódio; difamatória, não só com relação aos juđaizantes, mas contra toda uma linhagem.

Este é o posicionamento de Pulgar que transparece na sua Crônica. E, numa carta, dirigida ao cardeal Mendoza, comentando a expulsão dos judeus de Andaluzia e os acontecimentos nessa região, encontramos a melhor síntese do seu pensamento:

"[...] dias há muitos que no ânimo tenho escrito, e ainda com tinta ruim, a necedade tão cega e a cegueira tão néscia daquela gente, que achava bom e esperava o fruto que toda necedade pode dar de si. Também parece-me, senhor, que a Rainha, nossa senhora, faz o que deve como rainha cristianissima é obrigada a fazer, e não deve mais a Deus que mandá-lo, mas em como fiat istud pelos seus ministros vai todo o negócio"."

Pulgar tampouco acredita nos meios usados:

" PULGAR, Fernando del. Crónica de los Reyes Católicos. J. Mata Carriazo (Ed.) Madrid: EspasaCalpe, 1943, p. 336.

a PULGAR, F. "Carta inédita de Pulgar sobre la ejecución de los conversos al Arzobispo de Sevilla". In Crónica de los Reyes Católicos, op. cit., p. L. O sublinhado é nosso. 
"Devem ser bons [...] Diego Merlo (Corregedor de Sevilha) e o doutor Medina (Inquisidor), porém eu sei que eles não farão tão bons cristãos com o seu fogo como fizeram os bispos don Pablo e don Alonso com a sua agua"

Refere-se aqui a Pablo de Santa Maria (Salomon há-Levi antes da conversão) e a seu filho Alonso de Cartagena, ambos bispos de Burgos.

Acusado por manifestar-se contra os inquisidores, denunciando os seus erros, e ainda, de se opor à Rainha criticando as suas ordens, Pulgar defende-se das acusações justificando-se numa carta aberta:

\footnotetext{
"[...] porque nem eu digo que eles erraram no seu oficio, nem a Rainha nas suas comissões, embora fosse possivel que sua Alteza tivesse errado no empreendimento e ainda eles no procedimento, e tanto um como o outro não por má intenção, mas por equivocadas informações alheias"10
}

Apresenta uma série de exemplos dos equivocos cometidos por outros reis, entre os quais o próprio pai de Isabel ao entregar a administração de Toledo a Pero Sarmiento. E continua dirigindo-se ao anônimo acusador:

“assim que, senhor emendador, não é maravilha que sua Alteza se tenha enganado na comissão que fez, pensando que agia bem, e eles nos processos, pensando que não se informaram mal; embora eu não tenha dito nem agora afirme coisa nenhuma destas""

A verdade é que Pulgar disse o que queria dizer, utilizando magistralmente a linguagem e defendendo-se do perigo maior que podia causar a indignação da Rainha, sem renunciar aos seus princípios. Está muito claro que o cronista tinha emitido uma crítica grave sobre o governo e tinha tomado uma posição que respondia a uma corrente de opinião que, embora minoritária, era clara e existente.

A situação era incômoda, senão perigosa para o cronista, o qual, de fato, passa alguns anos afastado da Corte. Porém, volta novamente a ela respondendo ao chamado da Rainha, nada menos que com a encomenda de escrever a Crônica do seu reinado, cuja Primeira Parte termina em 1490. Por que nesse ano? O autor deixa-nos sem conhecer a sua opinião sobre a expulsão dos judeus em 1492. A Segunda Parte da Crônica de Pulgar dedica-se integralmente à Conquista de Granada.

Quanto à Crônica: Memória de los Reyes Católicos don Femando y doña Isabel de Anđrés Bernaldez, não foge do esquema geral da época com relação à imagem apresentada dos reis e, nas suas justificativas, vai além do panegírico, realizando uma autêntica apologia.

São poucas as notícias que se conhecem sobre a biografia deste cronista. Foi pároco numa pequena vila, Palacios, localizada na encomenda da Ordem de Santiago, de 1488 e 1513 e posteriomente, capelão do Arcebispo de Sevilha, o inquisidor don Diego Deza.

Bernaldez não pertencia ao círculo dos cronistas oficiais. A sua narrativa responde a um esquema mais simples e despretensioso. Ele mesmo explica que escreve para que "las cosas fazañosas" que tinha visto e ouvido e que não tinham

\footnotetext{
Idem. Toidem. p. II

PULGAR, F. "Carta a un amigo encubierto". In Crónica de los Reyes Católicos, op. cit., p. LVI

Idem, Boidem, p. LVII
} 
sido registradas em outros escritos, não fossem "esquecidas. Dirige-se "às gentes comuns". Muitos críticos consideram a sinceridade como um dos valores principais da sua Crônica. Situa-se entre os que defendem a Inquisição, cujas medidas aprova sem restrições. A expulsão dos judeus aparece como uma necessidade e a única forma de extirpar as raízes da heresia mosaica:

"E postos os reinos em muita justiça, acenderam o fogo contra os hereges, onde com justa razão, por sinodal constituição tem ardido, e arderão em vivas chamas até que não exista nenhum; e por mais ainda dar fim à heresia mosaica, tiraram-lhes as raizes, que eram as excomungadas sinagogas"12.

Apesar desse posicionamento, é um dos cronistas que oferece o quadro mais completo e trágico do exílio, năo isento de compaixão e sentimento, como indicam as suas palavras:

"Sairam das terras do seu nascimento, pequenos e grandes, velhos e crianças, a pé e cavaleiros em asnos e outras bestas e em carroças, e continuavam as suas viagens cada um em direção aos portos de destino, e iam pelos caminhos e campos por onde iam com muitos trabalhos e fortunas, uns caindo, outros levantando-se, outros morrendo, outros adoecendo; não havia cristão que não tivesse pena deles, e sempre por onde iam os convidavam ao batismo, e alguns com medo, convertiam-se e ficavam, mas muito poucos; e os rabinos os estimulavam e faziam cantar às mulheres e aos jovens e tanger os pandeiros e cuicas para alegrá-los, e assim saíram de Castela". ${ }^{13}$

Estes exemplos se, por um lado, denunciam uma situação de tragédia e incompreensão que encontramos tanto em Fernando del Pulgar como em Andres Bernaldez, por outro, demonstram o que indicávamos inicialmente. As crônicas cristãs da época silenciam a expulsão dos judeus ou, quando falam dela, a justificam.

\footnotetext{
BERNALDEZ, A. op. cit., p. 574
}

Idem, Ibidem, p. 653. 